\title{
Semiconductors as Heterogeneous Visible Light Photoredox Catalysts in Combined Dual Metal Catalyzed C-H Functionalizations
}

\author{
David C. Fabry, ${ }^{\mathrm{a}, \mathrm{c} *}$ Jochen Zoller, ${ }^{\mathrm{a}}$ Magnus Rueping ${ }^{\mathrm{b} *}$ \\ ${ }^{a}$ Institute of Organic Chemistry, RWTH Aachen University, Landoltweg 1, Aachen D-52074, Germany \\ ${ }^{b}$ King Abdullah University of Science and Technology (KAUST), KAUST Catalysis Center (KCC), Thuwal \\ 23955-6900, Saudi Arabia \\ 'Tokyo Institute of Technology, Department of Chemistry, Ookayama, 2-12-1-NE-1, Meguro-ku, Tokyo \\ 152-8550, Japan
}

Keywords: Heterogeneous catalysis $\bullet$ bismuth vanadate $\bullet$ tungsten oxide $\bullet$ olefination $\bullet$ oxidant

\begin{abstract}
The application of heterogeneous semiconductors as catalyts for $\mathrm{C}-\mathrm{H}$ functionalization reactions is presented. Visible light enables electron transfer processes for transition metal catalyzed olefination reactions providing important synthesis core structures in generally good yields. The methodology provides an elegant and sustainable alternative to otherwise stoichiometrically applied transition metal additives.
\end{abstract}

\section{Introduction}

Heterogeneous photocatalysis has a long history mainly focussing on the activation of suitable semiconductors with UV light.[1-5] The most prominent example is titanium dioxide $\left(\mathrm{TiO}_{2}\right)$ that can be used as UV-sensitizer.[6-10] Due to its non-toxicity, its low price, and the deep knowledge of surface reactions, it is highly suitable for organic reactions, including oxidation reactions.[11-17] However, a disadvantage is the use of high energy UV light that may not be compatible with organic or highly functionalized target molecules due to UV light mediated side-reactions or decompositions.

In recent years, alternatives have been developed to shift the light excitation range towards visible light that represents an abundant and mild energy source and is often compatible with organic substrates and products. Approaches towards $\mathrm{TiO}_{2}$ modifications with nanoparticles, antenna molecules, or dotation led to improved catalysts.[18-21] Recently we also made use of in-situ surface modifications of $\mathrm{TiO}_{2}$, thereby allowing the visible arylation with diazonium salts,[22] both in batch and flow setups.[23, 24]. In addition the oxidation of $\mathrm{N}$-tetrahydroisoquinolines and subsequent functionalization with various nucleophiles were possible.[25] In the context of more elaborate synthesis Koenig et al. reported further heterogeneous, visible light active photoredox catalysts. [22] $\mathrm{CdS}$ or $\mathrm{PbBiO}_{2} \mathrm{Br}$ were used in the visible light photoredox catalyzed alkylation of aldehydes with bromomalonates.

In recent years, metal catalyzed $\mathrm{C}-\mathrm{H}$ functionalizations have become an important tool in organic synthesis. However, often stoichiometric amounts of metal-based oxidants such as copper or silver salts are needed for the regeneration of the active metal catalyst. Hence, we wondered if visible light active semiconductors with the appropriate band gap and reduction potential could also facilitate the regeneration of the active metal catalyst leading to more efficient and sustainable in $\mathrm{C}-\mathrm{H}$ functionalization reactions. [26-32] Based on literature reports, bismuth vanadate $\left(\mathrm{BiVO}_{4}\right)$ [33] (band gap: $2.4 \mathrm{eV}$ ) and tungsten oxide $\left(\mathrm{WO}_{3}\right)$ [34] (2.6-3.0 eV) seemed to be a good starting point for investigations. Both oxides are typically used in the field of pigment and material chemistry [35-37], 
absorb visible light and possess reduction potentials similar to homogeneous photoredox catalysts. [3841]

\section{Experimental}

\section{Materials and Methods}

All commercially available chemicals were used as provided by the suppliers without further treatment. All solvents were dried and distilled under argon prior to use. Solvents for chromatography were technical grade and distilled prior to use. Analytical thin-layer chromatography (TLC) was performed on Macherey-Nagel ALUGRAM Xtra SIL G/UV254 aluminum plates with F-254 indicator, visualized by UV irradiation. Macherey-Nagel silica gel 60 (particle size $0.063-0.2 \mathrm{~mm}$ ) was used for column chromatography. Solvent mixtures are understood as volume/volume. An $11 \mathrm{~W}$ fluorescent bulb, warm white, was used for irradiation with light. All reactions concerning the scope were repeated at least twice. 1H NMR, 13C NMR and 19F NMR spectra were recorded on VNMRS-400, VNMRS-600 or Mercury 300 spectrometer in $\mathrm{CDCl} 3$. Chemical shifts $(\delta)$ are reported in ppm and multiplicities are indicated: $s$ (singlet), d (doublet), dd (doublet of doublet, $t$ (triplet), dt (doublet of triplet), td (triplet of doublet), $q$, (quartet), quint (quintet) $\mathrm{m}$ (multiplet); coupling constants $(J)$ are in Hertz (Hz). Mass spectra (MS-El: 70 eV were conducted on a Finnigan MET SSQ 7000 system, LCMS spectra on a LTQ Orbitrap XL spectrometer and HRMS spectra on a Thermo Scientific LTQ Orbitrap XL spectrometer. IR spectra (ATR) were recorded on a Perkin Elmer spectrometer and wave numbers are given in reciprocal centimeters (cm-1). Starting materials were synthesized according to literature-known procedures and the products compared to literature known compounds. [42-44]

\section{General procedure for the Ru-catalyzed olefination}

The respective educt (1 equiv.) and acrylate (2 equiv.), Ru-catalyst (5 mol\%), AgSbF6 (0.2 equiv.) and photoredox catalyst (10 mol\% or 1 equiv.) were dissolved in DMA (0.1 M). A $4 \mathrm{~mL}$ vial equipped with a teflon-coated magnetic stirring bar served as reaction vessel. The mixture was irradiated by an $11 \mathrm{~W}$ lamp (distance ca. $3 \mathrm{~cm}$ ) after placing it on an aluminium block heated at $120{ }^{\circ} \mathrm{C}$. The reaction was quenched with $2 \mathrm{~mL}$ of $10 \%$ aqueous $\mathrm{LiCl}$ solution, after complete consumption of substrate (followed by TLC). The aqueous layer was then extracted with DCM $(5 \times 20 \mathrm{~mL})$ and the combined organic layer dried over MgSO4. After removal of solvents, the crude product was purified by flash column chromatography.

\section{General procedure for the Pd-catalyzed cyclization}

In a $4 \mathrm{~mL}$ vial equipped with a teflon-coated magnetic stirring bar, the appropriate $\mathrm{N}$-aryl enamide (1 equiv.), $\mathrm{Pd}(\mathrm{OAc})_{2}(10 \mathrm{~mol} \%), \mathrm{K}_{2} \mathrm{CO}_{3}$ (3 equiv.) and photoredox catalyst (10 mol\%, 1 equiv.) were dissolved in DMF (0.1 M) and the reaction mixture placed in front of an $11 \mathrm{~W}$ household lamp (distance ca. $3 \mathrm{~cm}$ ) on an aluminium block heated at $120^{\circ} \mathrm{C}$. After complete consumption of starting material (followed by $\mathrm{TLC}$ ), the reaction was quenched with $2 \mathrm{~mL}$ of $10 \%$ aqueous $\mathrm{LiCl}$ solution, the aqueous layer extracted with DCM $(5 \times 20 \mathrm{~mL})$ and the combined organic layer dried over $\mathrm{MgSO}_{4}$. After removal of solvents, the crude product was purified by flash column chromatography.

\section{General procedure for the Rh-catalyzed olefination}

A $4 \mathrm{~mL}$ vial was equipped with the corresponding Weinreb amide (1 equiv.), $\left[\mathrm{RhCp}^{*} \mathrm{Cl}_{2}\right]_{2}(1.0 / 2.5 \mathrm{~mol} \%)$ and photoredox catalyst (10 mol\%, 1 equiv.) and a teflon-coated magnetic stirring bar. After addition of 
$\mathrm{AgSbF}_{6}(5 / 10 \mathrm{~mol} \%)$ in chlorobenzene $(0.01 \mathrm{mM})$ the corresponding electrophile (2 equiv.) was added and the reaction mixture placed in a preheated aluminum block $\left(100^{\circ} \mathrm{C}\right.$, actual vial temperature $\left.\sim 80^{\circ} \mathrm{C}\right)$ under light irradiation from ca. $3 \mathrm{~cm}$ distance. After the indicated time, the reaction mixture was directly absorbed on $\mathrm{SiO}_{2}$ and the product purified by flash column chromatography.

\section{Results and Discussion}

In order to test our hypothesis, we decided to investigation metal catalyzed $\mathrm{C}-\mathrm{H}$ olefination reactions (Scheme 1).

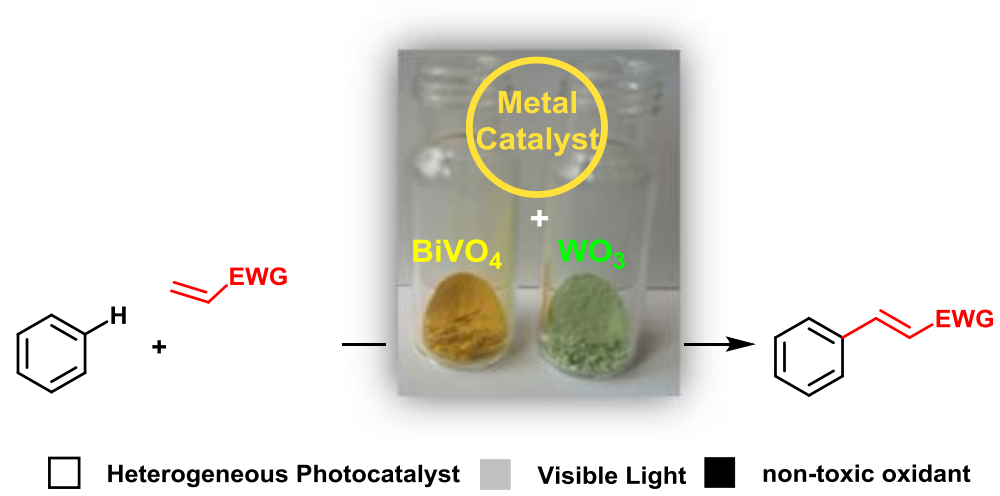

Scheme 1. Heterogeneous oxidants for $\mathrm{C}-\mathrm{H}$ functionalization reactions.

Mechanistically, we assumed that the semiconductor could act as a visible light photoredox catalyst and thus would be a suitable replacement for the previously reported metal salts (Scheme 2). A catalytic cycle would begin with metal catalyst $\mathbf{A}$ that inserts into an aryl- $\mathbf{H}$ bond to give intermediate $\mathbf{B}$. The following olefin insertion results in formation of $\mathbf{C}$ which upon reductive elimination provides the reduced metal catalyst $\mathbf{D}$ that needs to be oxidized in order to reenter the catalytic cycle.

We proposed that electron holes in the valence and conducting band of the semiconductor enabled by visible light irradiation, could accept those electrons coming from the reduced metal species to generate the active $\mathrm{C}-\mathrm{H}$ activation catalyst. As model reaction we decided to examine the previously reported ortho-olefination of protected phenols $[42,45]$ and evaluated different visible-light absorbing heterogeneous semiconductors (Table 1, entry 1-3). We were pleased to see that in general conversion of the substrate $\mathbf{1} \mathbf{a}$ to the corresponding product $\mathbf{2} \mathbf{b}$ could be observed. To our delight, we found that use 1 equivalent of $\mathrm{BiVO}_{4}$ provided the desired product in good yield (Table 1, entry 3). To validate if a catalytic reaction could be performed, 0.1 equivalent of $\mathrm{BiVO}_{4}$ was applied as the heterogeneous photoredox catalyst and indeed, $71 \%$ yield of the product was obtained at an increased scale of 0.3 mmol (Table 1, entry 4). This shows that the reaction cannot only be performed under truly catalytic conditions, but that scaling can be accomplished without loss of performance. 


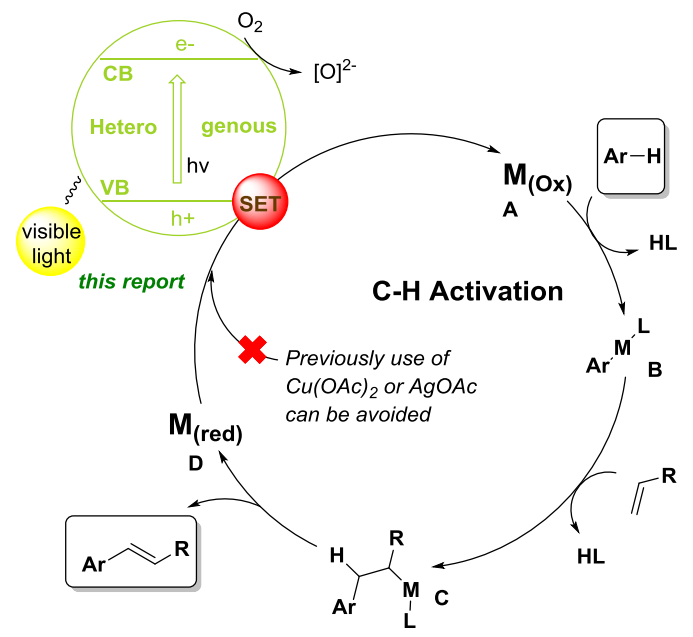

Scheme 2. Mechanistic proposal for heterogeneous C-H functionalization reactions.

Table 1. Catalyst screening and control reactions for the heterogeneous photoredox catalyzed $\mathrm{CH}$ olefination.

\begin{tabular}{|c|c|c|}
\hline Entry $^{a}$ & Photocatalyst & Yield $^{b}$ \\
\hline 1 & $\mathrm{WO}_{3}$ & $53 \%$ \\
\hline 2 & $\mathrm{TiO}_{2}$ & $14 \%$ \\
\hline 3 & $\mathrm{BiVO}_{4}$ & $84 \%$ \\
\hline 4 & $\mathrm{BiVO}_{4}$ & $71 \%^{\mathrm{c}}$ \\
\hline 5 & $\mathrm{BiVO}_{4}$ & $18 \%^{d}$ \\
\hline 6 & $\mathrm{BiVO}_{4}$ & $49 \%^{\mathrm{e}}$ \\
\hline 7 & {$\left[\operatorname{Ir}(\text { ppy })_{2}(\mathrm{bpy})\right]\left(\mathrm{PF}_{6}\right)$} & $75 \%^{f}$ \\
\hline 8 & $\mathrm{BiVO}_{4}$ & $5 \%^{\mathrm{g}}$ \\
\hline
\end{tabular}

[a] Standard conditions: phenol $(0.1 \mathrm{mmol}), 1.0$ equiv photocatalyst under air, irradiation with $11 \mathrm{~W} C F \mathrm{~L}$ lamp; [b] yield of isolated product; [c] $0.3 \mathrm{mmol}$ phenol, 0.1 equiv $\mathrm{BiVO}_{4}$ air, $36 \mathrm{~h}$, [d] 0.1 equiv $\mathrm{BiVO}_{4}$ argon, $36 \mathrm{~h}$, [e] 1.0 equiv $\mathrm{BiVO}_{4}$ argon, [f] 3 mol\% Ir-cat, $48 \mathrm{~h}$; see ref. [42], [g] 1.0 equiv $\mathrm{BiVO}_{4}$ under air no light.

Further control reactions were conducted regarding the role of oxygen. When 0.1 equivalents of semiconductor in presence of argon was applied, only $18 \%$ yield of the product could be isolated (entry $5)$, indicating oxygen plays a crucial role in the reaction. With 1 equivalent of $\mathrm{BiVO}_{4}$ under the same conditions (Table 1, entry 6), stoichiometric conversion with regard to the amount of heterogeneous catalyst was observed. Please note that the regeneration of the reactive Ru catalyst is a 2-electron redox process and as such the use of 1 equivalent of $\mathrm{BiVO}_{4}$ can theoretically lead to $50 \%$ yield. Thus, this results reveals that $\mathrm{BiVO}_{4}$ can serve as 1-eletron transfer reagent that needs oxygen in order to regenerate its oxidized form. Interestingly, the heterogeneous system delivered the product in half the time if compared to the homogeneous system using $\left[\operatorname{Ir}(\mathrm{ppy})_{2}(\mathrm{bpy})\right]\left(\mathrm{PF}_{6}\right)$ as photoredox catalyst (Table 1 , entry 7).

A final control reaction showed that in the absence of light no catalytic reaction is observed (Table 1, entry 8). Thus, for the first time we were able to demonstrate that $\mathrm{BiVO}_{4}$ can act as an efficient visible 
light photoredox catalyst that can be coupled to enable a Ru-catalyzed $\mathrm{C}-\mathrm{H}$ olefination. With the optimized reaction conditions for the ortho-olefination in hand, various substrates were tested (Table 2). We were pleased to see different substituted phenols as well as acrylates could be efficiently converted into their olefinated counterparts (2a-e) in good to very good yields demonstrating that this dual catalytic process can be valuable alternative to the use of stochiometric oxidants in $\mathrm{C}-\mathrm{H}$ olefinations.

Table 2. Scope of the ortho-olefination of phenolethers by combining heterogeneous photoredox and Ru-catalysis.

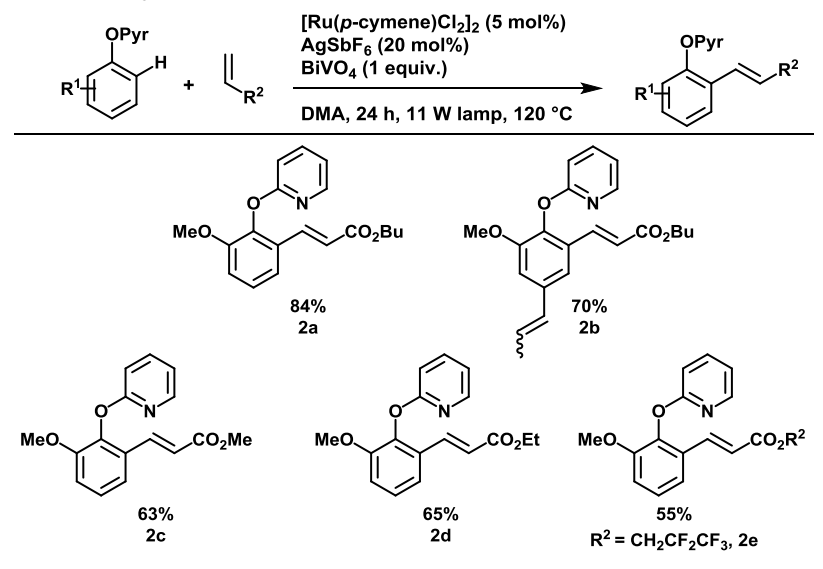

[a] Reaction conditions: substrate $(0.2 \mathrm{mmol}), 2 \mathrm{~mL}$ DMA, irradiation with $11 \mathrm{~W}$ CFL lamp.

In order to extend this combined photoredox and metal catalysis concept to other transition metals we decided to evaluate the compatibility with palladium catalyzed $\mathrm{C}-\mathrm{H}$ functionalizations. Hence, the intramolecular ring-closing reaction of enamides (3a) to pharmaceutically interesting indole [46-51] core structures (4) was targeted. $[44,52]$ While the use of $\mathrm{WO}_{3}$ did only provide low yields (Table 3 , entry 2 ) we were pleased to see that also here $\mathrm{BiVO}_{4}$ (Table 3, entry 1 ), both in catalytic and stoichiometric fashion furnished the desired indole (4a) in high yields of $81 \% / 82 \%$, respectively.

Table 3. Catalyst screening for the heterogeneous photoredox catalyzed indole synthesis.

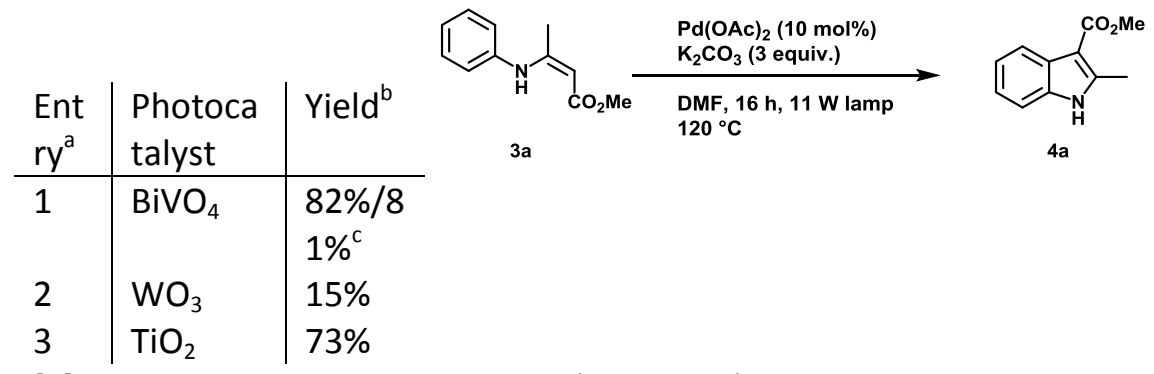

[a] Standard conditions: enamine $(0.1 \mathrm{mmol}), 1.0$ equiv photocatalyst under air, irradiation with $11 \mathrm{~W}$ CFL lamp; [b] yield of isolated product; [c] 0.5 mmol enamine, 0.1 equiv $\mathrm{BiVO}_{4}$ air.

In order to evaluated the applicability of the combined semiconductor and Pd-catalysis procedure we tested different substitution patterns at the enamide substrate (Table 4). We were pleased to see that both electron-withdrawing (4d) as well as donating groups (4b-c) are well-tolerated delivering the corresponding indole motifs in good to very good yields (Table 4). Also in the indole-9 position, electron 
donating and withdrawing groups could be successfully applied in the cyclization reaction (4e-f). Finally, the ester part was varied yielding a tert-butyl ester in $71 \%$ yield $(\mathbf{4 g})$.

Table 4. Scope of the heterogeneous photoredox catalyzed enamine cyclization in combination with Pdcatalysis.

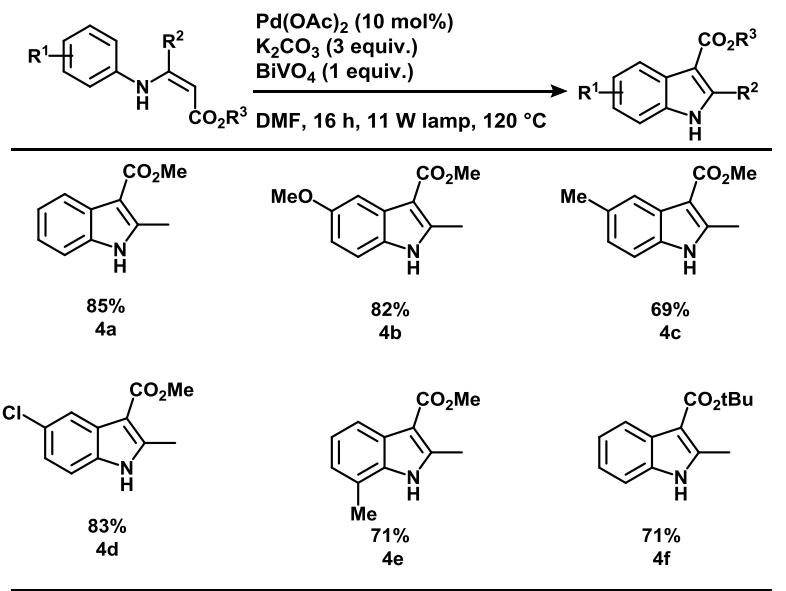

[a] Reaction conditions: substrate $(0.2 \mathrm{mmol}), 2 \mathrm{~mL} D M F$, irradiation with $11 \mathrm{~W}$ CFL lamp.

Having successfully demonstrated that bismuth vanadate is a compatible visible light photoredox catalyst in $\mathrm{Ru}$ and $\mathrm{Pd}$ catalyzed $\mathrm{CH}$-functioalizations we wondered if also Rh-catalyzed olefinations would be amenable to the dual catalysis concept. Hence, we examined the rhodium-catalyzed orthoolefinations of arylamides (Table 5). [43, 53]

Table 5. Catalyst screening and control reactions for the heterogeneous photoredox catalyzed Weinreb olefination.

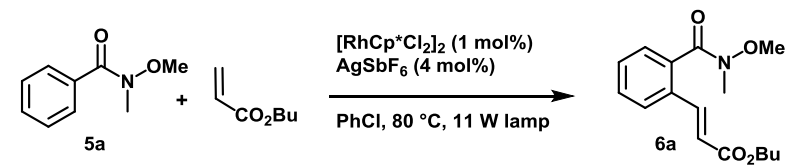

\begin{tabular}{l|l|l} 
Entry $^{\mathrm{a}}$ & Photocatalyst & Yield $^{\mathrm{b}}$ \\
\hline 1 & $\mathrm{BiVO}_{4}$ & $58 \%$ \\
2 & $\mathrm{WO}_{3}$ & $84 \% / 81 \%^{\mathrm{c}}$
\end{tabular}

[a] Standard conditions: amide $(0.1 \mathrm{mmol}), 1.0$ equiv photocatalyst under air, irradiation with $11 \mathrm{~W}$ CFL lamp $24 \mathrm{~h}$; [b] yield of isolated product; [c] 0.5 mmol amide, 0.1 equiv $\mathrm{WO}_{3}$ air, $36 \mathrm{~h}$.

In contrast to the previous reactions, not bismuth vanadate (Table 5 , entry $1,58 \%$ yield), but $\mathrm{WO}_{3}$ provided the highest yield of the olefination product 6 a with $84 \%$ yield for a stoichiometric reaction and $81 \%$ yield for a catalytic reaction. The latter reaction was moreover realized at gram-scale in order to guarantee enough photo-absorbing catalyst in the reaction due to the high molecular weight of the semiconductor (Table 5, entry 2). With the optimized reaction conditions, we tested the scope by varying the aryl substituents and amide groups. Similar to the previous cases, generally a good functional group tolerance was observed allowing the efficient synthesis of olefinated Weinreb (6a-c) and alkyl amides (6d-g) (Table 6). 
Table 6. Scope of the heterogeneous photoredox catalyzed Weinreb and alkylamide olefination using Rh-catalysis.

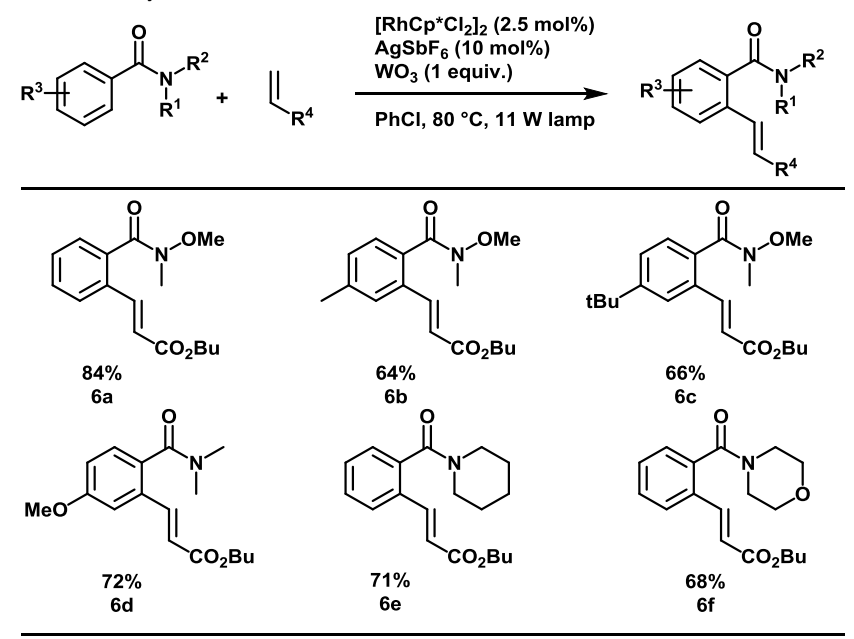

[a] Reaction conditions: substrate $(0.2 \mathrm{mmol}), 2 \mathrm{~mL} \mathrm{PhCl}$, irradiation with $11 \mathrm{~W}$ CFL lamp, $24 \mathrm{~h}$.

\section{Conclusion}

In summary, we report for the first time the use of heterogeneous semiconductors as visible-light photoredox catalysts for transition metal catalysed $\mathrm{C}-\mathrm{H}$ olefination reactions. The three most common metals for catalytic $\mathrm{C}-\mathrm{H}$ functionalizsations, $\mathrm{Pd}, \mathrm{Rh}$, and $\mathrm{Ru}$, could be successfully applied in the dual catalytic visible light driven process. Thereby, commonly applied oxidants can be avoided and replaced with heterogenous photocatalysts. Given that the semicondutors, $\mathrm{BiVO}_{4}$ and $\mathrm{WO}_{3}$, are i) cheaper as the often used homogeneous Ir oder Ru-photocatalysts, ii) stable under the different reaction conditions, iii) easily used and separated from the reaction mixture and, iv) compatible with different transition metal catalysts, we anticipate this dual catalysis concept will contribute to the development of further sustainable methodologies and procedures.

\section{References}

[1] Y. Wang, A.A. Liu, D.G. Ma, S.H. Li, C.C. Lu, T. Li, C.C. Chen, TiO2 Photocatalyzed C-H Bond Transformation for C-C Coupling Reactions, Catalysts, 8 (2018).

[2] F. Parrino, M. Bellardita, E.I. Garcia-Lopez, G. Marci, V. Loddo, L. Palmisano, Heterogeneous Photocatalysis for Selective Formation of High-Value-Added Molecules: Some Chemical and Engineering Aspects, ACS Catal., 8 (2018) 11191-11225.

[3] D. Heggo, S. Ookawara, Multiphase photocatalytic microreactors, Chem. Eng. Sci., 169 (2017) 67-77.

[4] J.C. Colmenares, R. Luque, Heterogeneous photocatalytic nanomaterials: prospects and challenges in selective transformations of biomass-derived compounds, Chem. Soc. Rev., 43 (2014) 765-778.

[5] A.G. Griesbeck, M. Oelgemöller, F. Ghetti, CRC Handbook of Organic Photochemistry and Photobiology, 2012.

[6] M. Nasr, C. Eid, R. Habchi, P. Miele, M. Bechelany, Recent Progress on Titanium Dioxide Nanomaterials for Photocatalytic Applications, ChemSusChem, 11 (2018) 3023-3047.

[7] L.V. Bora, R.K. Mewada, Visible/solar light active photocatalysts for organic effluent treatment: Fundamentals, mechanisms and parametric review, Renewable Sustainable Energy Rev., 76 (2017) 13931421.

[8] A. Fujishima, X.T. Zhang, D.A. Tryk, TiO2 photocatalysis and related surface phenomena, Surf. Sci. Rep., 63 (2008) 515-582. 
[9] K. Hashimoto, H. Irie, A. Fujishima, TiO2 photocatalysis: A historical overview and future prospects, Jpn. J. Appl. Phys., Part 1, 44 (2005) 8269-8285.

[10] M. Grätzel, Dye-sensitized solar cells, J. Photochem. Photobiol., C, 4 (2003) 145-153.

[11] B. Pieber, M. Shalom, M. Antonietti, P.H. Seeberger, K. Gilmore, Continuous Heterogeneous Photocatalysis in Serial Micro-Batch Reactors, Angew. Chem. Int. Ed., 57 (2018) 9976-9979.

[12] N. Hoffmann, Photocatalysis with TiO2 Applied to Organic Synthesis, Austral. J. Chem., 68 (2015).

[13] H. Kisch, Semiconductor photocatalysis--mechanistic and synthetic aspects, Angew. Chem. Int. Ed., 52 (2013) 812-847.

[14] F. Parrino, A. Ramakrishnan, H. Kisch, Sulfoxidation von Alkanen durch Halbleiterphotokatalyse, Angewandte Chemie, 120 (2008) 7215-7217.

[15] H. Kisch, Advances in Photochemistry, Vol. 26: SEMICONDUCTOR PHOTOCATALYSIS FOR ORGANIC SYNTHESIS, John Wiley \& Sons, Inc., 2001.

[16] H. Keck, W. Schindler, F. Knoch, H. Kisch, Type B Semiconductor Photocatalysis : The Synthesis of Homoallyl Amines by Cadmium Sulfide-Catalyzed Linear Photoaddition of Olefins, (1997) 1638-1645.

[17] J.A. Caputo, L.C. Frenette, N. Zhao, K.L. Sowers, T.D. Krauss, D.J. Weix, General and Efficient C - C Bond Forming Photoredox Catalysis with Semiconductor Quantum Dots, J. Am. Chem. Soc. 139 (2017) 4250-4253.

[18] H. Hao, L. Zhang, W. Wang, S. Zeng, Modification of heterogeneous photocatalysts for selective organic synthesis, Catal. Sci. Technol., 8 (2018) 1229-1250.

[19] V. Likodimos, Photonic crystal-assisted visible light activated TiO 2 photocatalysis, Appl. Catal., B, 230 (2018) 269-303.

[20] D. Mitoraj, H. Kisch, The nature of nitrogen-modified titanium dioxide photocatalysts active in visible light, Angew. Chem. Int. Ed., 47 (2008) 9975-9978.

[21] M. Gartner, V. Dremov, P. Muller, H. Kisch, Bandgap widening of titania through semiconductor support interactions, Chemphyschem, 6 (2005) 714-718.

[22] A. Pfitzner, K. Zeitler, B. Koenig, Visible-Light-Promoted Stereoselective Alkylation by Combining Heterogeneous Photocatalysis with Organocatalysis, Angew. Chem. Int. Ed., 51 (2012) 4062-4066.

[23] D.C. Fabry, Y.A. Ho, R. Zapf, W. Tremel, M. Panthöfer, M. Rueping, T.H. Rehm, Blue light mediated $\mathrm{C}-\mathrm{H}$ arylation of heteroarenes using $\mathrm{TiO} 2$ as an immobilized photocatalyst in a continuous-flow microreactor, Green Chem., 19 (2017) 1911-1918.

[24] J. Zoller, D.C. Fabry, M. Rueping, Unexpected Dual Role of Titanium Dioxide in the Visible Light Heterogeneous Catalyzed C-H Arylation of Heteroarenes, ACS Catal., 5 (2015) 3900-3904.

[25] C. Vila, M. Rueping, Visible-light mediated heterogeneous $\mathrm{C}-\mathrm{H}$ functionalization: oxidative multicomponent reactions using a recyclable titanium dioxide (TiO2) catalyst, Green Chem., 15 (2013) 2056.

[26] H. Yi, G. Zhang, H. Wang, Z. Huang, J. Wang, A.K. Singh, A. Lei, Recent Advances in Radical C-H Activation/Radical Cross-Coupling, Chem. Rev., 117 (2017) 9016-9085.

[27] J. He, M. Wasa, K.S.L. Chan, Q. Shao, J.Q. Yu, Palladium-Catalyzed Transformations of Alkyl C-H Bonds, Chem. Rev., 117 (2017) 8754-8786.

[28] B. Ye, N. Cramer, Chiral Cyclopentadienyls: Enabling Ligands for Asymmetric Rh(III)-Catalyzed C-H Functionalizations, Acc. Chem. Res., 48 (2015) 1308-1318.

[29] L. Ackermann, Carboxylate-assisted ruthenium-catalyzed alkyne annulations by $\mathrm{C}-\mathrm{H} / \mathrm{Het}-\mathrm{H}$ bond functionalizations, Acc. Chem. Res., 47 (2014) 281-295.

[30] J. Wencel-Delord, F. Glorius, C-H bond activation enables the rapid construction and late-stage diversification of functional molecules, Nat Chem, 5 (2013) 369-375.

[31] W.R. Gutekunst, P.S. Baran, C-- -H functionalisation in organic synthesis themed issue, 40 (2011).

[32] L. Ackermann, Carboxylate-assisted transition-metal-catalyzed $\mathrm{C}-\mathrm{H}$ bond functionalizations: mechanism and scope, Chem. Rev., 111 (2011) 1315-1345. 
[33] S.S. Dunkle, R.J. Helmich, K.S. Suslick, BiVO 4 as a Visible-Light Photocatalyst Prepared by Ultrasonic Spray Pyrolysis, (2009) 11980-11983.

[34] P.P. González-Borrero, F. Sato, A.N. Medina, M.L. Baesso, A.C. Bento, G. Baldissera, C. Persson, G.A. Niklasson, C.G. Granqvist, A. Ferreira da Silva, Optical band-gap determination of nanostructured WO3 film, Appl. Phys. Lett., 96 (2010) 061909.

[35] X. Ding, X. Yang, Z. Xiong, H. Chen, L. Zhang, Environment Pollutants Removal with Bi-Based Photocatalysts, PROGRESS IN CHEMISTRY, 29 (2017) 1115-1126.

[36] A. Malathi, J. Madhavan, M. Ashokkumar, P. Arunachalam, A review on BiVO4 photocatalyst: Activity enhancement methods for solar photocatalytic applications, Appl. Catal., A, 555 (2018) 47-74.

[37] Z.-F. Huang, J. Song, L. Pan, X. Zhang, L. Wang, J.-J. Zou, Tungsten Oxides for Photocatalysis , Electrochemistry, and Phototherapy, (2015) 5309-5327.

[38] C. Michelin, N. Hoffmann, Photosensitization and Photocatalysis-Perspectives in Organic Synthesis, ACS Catal., 8 (2018) 12046-12055.

[39] C. K. Prier, D. A. Rankic, D. W. C. MacMillan, Visible Light Photoredox Catalysis with Transition Metal Complexes: Applications in Organic Synthesis, Chem. Rev. 113 (2013), 5322-5363.

[40] C. Michelin, N. Hoffmann, Photocatalysis applied to organic synthesis - A green chemistry approach, Curr. Opin. Green Sustainable Chem., 10 (2018) 40-45.

[41] S. Protti, M. Fagnoni, A. Albini, Photochemical Synthesis, in: W. Zhang, B.W. Cue (Eds.) Green Techniques for Organic Synthesis and Medicinal Chemistry, John Wiley \& Sons, 2018.

[42] D.C. Fabry, M.A. Ronge, J. Zoller, M. Rueping, C-H functionalization of phenols using combined ruthenium and photoredox catalysis: in situ generation of the oxidant, Angew. Chem. Int. Ed., 54 (2015) 2801-2805.

[43] D.C. Fabry, J. Zoller, S. Raja, M. Rueping, Combining rhodium and photoredox catalysis for C-H functionalizations of arenes: oxidative Heck reactions with visible light, Angew. Chem. Int. Ed., 53 (2014) 10228-10231.

[44] J. Zoller, D.C. Fabry, M.A. Ronge, M. Rueping, Synthesis of indoles using visible light: photoredox catalysis for palladium-catalyzed C-H activation, Angew. Chem. Int. Ed., 53 (2014) 13264-13268.

[45] W. Ma, L. Ackermann, Ruthenium(II)-Catalyzed C-H Alkenylations of Phenols with Removable Directing Groups, Chem. Eur. J., 19 (2013) 13925-13928.

[46] C.H. Wang, Y.H. Li, S.D. Yang, Autoxidation Photoredox Catalysis for the Synthesis of 2Phosphinoylindoles, Org Lett, 20 (2018) 2382-2385.

[47] M. Teders, L. Pitzer, S. Buss, F. Glorius, Regioselective Synthesis of 2-Substituted indoles from Benzotriazoles and Alkynes by Photoinitiated Denitrogenation, ACS Catal., 7 (2017) 4053-4056.

[48] Y.Y. Liu, X.Y. Yu, J.R. Chen, M.M. Qiao, X. Qi, D.Q. Shi, W.J. Xiao, Visible-Light-Driven Aza-orthoquinone Methide Generation for the Synthesis of Indoles in a Multicomponent Reaction, Angew. Chem. Int. Ed., 56 (2017) 9527-9531.

[49] W.Q. Liu, T. Lei, Z.Q. Song, X.L. Yang, C.J. Wu, X. Jiang, B. Chen, C.H. Tung, L.Z. Wu, Visible Light Promoted Synthesis of Indoles by Single Photosensitizer under Aerobic Conditions, Org Lett, 19 (2017) 3251-3254.

[50] L. Gu, C. Jin, W. Wang, Y. He, G. Yang, G. Li, Transition-metal-free, visible-light induced cyclization of arylsulfonyl chlorides with o-azidoarylalkynes: a regiospecific route to unsymmetrical 2,3-disubstituted indoles, Chem. Commun., 53 (2017) 4203-4206.

[51] C.J. Wu, Q.Y. Meng, T. Lei, J.J. Zhong, W.Q. Liu, L.M. Zhao, Z.J. Li, B. Chen, C.H. Tung, L.Z. Wu, An Oxidant-Free Strategy for Indole Synthesis via Intramolecular C-C Bond Construction under Visible Light Irradiation: Cross-Coupling Hydrogen Evolution Reaction, ACS Catal., 6 (2016) 4635-4639.

[52] S. Würtz, S. Rakshit, J.J. Neumann, T. Dröge, F. Glorius, Palladium-Catalyzed Oxidative Cyclization of N-Aryl Enamines: From Anilines to Indoles, Angew. Chem. Int. Ed., 47 (2008) 7230-7233. 
[53] Y. Wang, C. Li, Y. Li, F. Yin, X.-S. Wang, Rhodium-Catalyzed C-H Olefination of Aryl Weinreb Amides, Adv. Synth. Catal., 355 (2013) 1724-1728.

\section{Graphical Abstract}

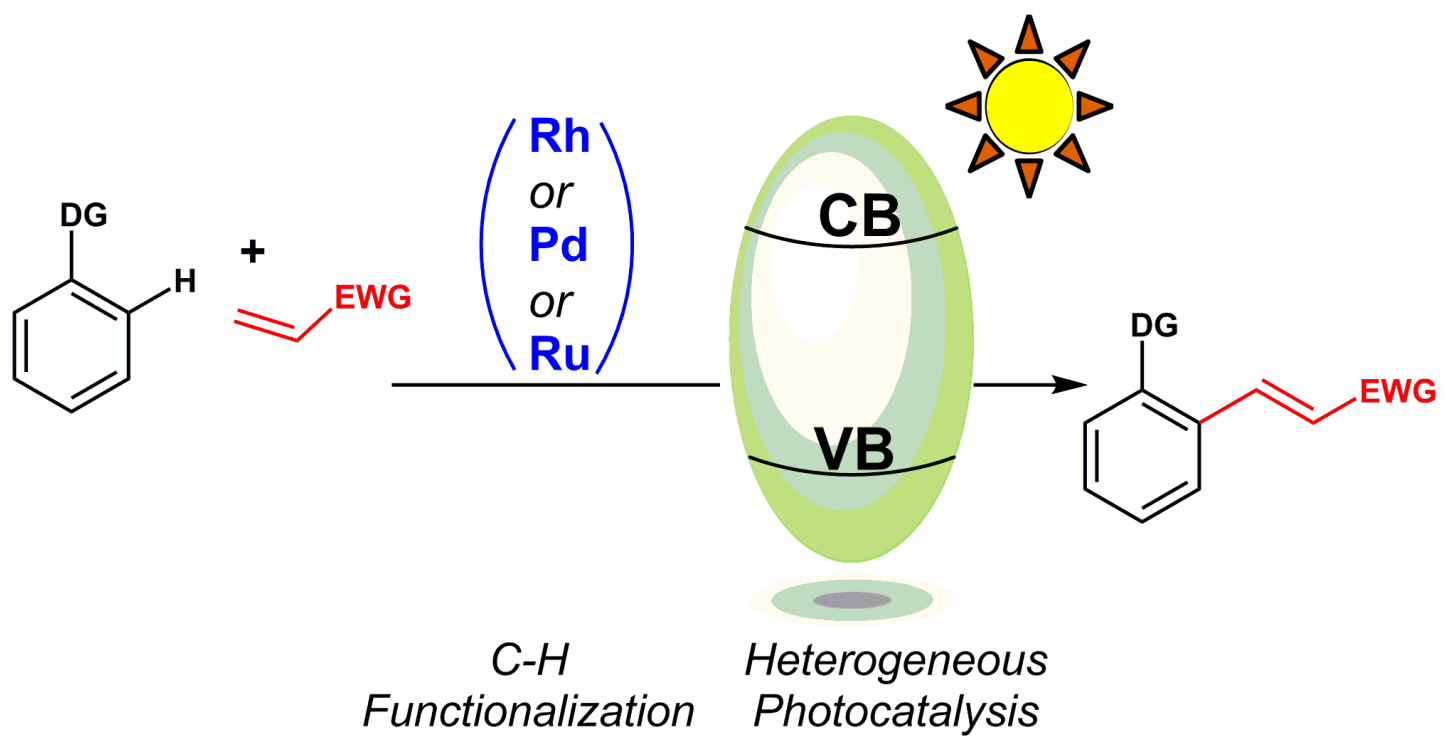

